\title{
Formation of microstructures in Ti-Cr-V alloys with high hydrogen sorption capacity
}

\author{
N.E. SKRYABINA ${ }^{1}$, D. FRUCHART ${ }^{2}$, N.A. MEDVEDEVA ${ }^{1}$, P. DE RANGO ${ }^{2}$, A.A. MIRONOVA ${ }^{1}$ \\ ${ }^{1}$ Perm State University, Bukireva St. 15, Perm, 614990, Russia \\ ${ }^{2}$ Institut Néel, CNRS, BP 166, 38042 Grenoble Cedex 9, France \\ *Corresponding author. E-mail: natskryabina@mail.ru
}

Received November 29, 2016; accepted December 28, 2016; available on-line August 14, 2017

TiVCr alloys known for their potentially large hydrogen uptake were formulated as $\left(\operatorname{TiCr}_{1.8}\right)_{100-x} \mathrm{~V}_{x}$ in order to quantify the impact of the vanadium concentration. Parallel to this series of pure ternaries, a second one was synthesized with $4 \mathrm{~mol} . \%$ of $\mathrm{Zr}_{7} \mathrm{Ni}_{10}$ addition. Structural investigation and electrochemical charging with hydrogen revealed a fair dependence of the hydrogen uptake and hydride stability on the vanadium content, but conversely different due to the presence of the $\mathrm{Zr}$-Ni additive.

B.c.c. alloys / Zr-Ni additive / Microstructure / Hydrogen sorption / Electrochemical properties

\section{Introduction}

During the past 15 years, many research activities have been devoted to the b.c.c. $\operatorname{Ti}_{\alpha} \mathrm{V}_{\beta} \mathrm{Cr}_{\gamma}(\alpha+\beta+\gamma=$ 100) series of alloys since they can exhibit a hydrogen uptake better than most intermetallics. Indeed, for the $\mathrm{Ti}_{\alpha} \mathrm{V}_{\beta} \mathrm{Cr}_{\gamma}$ alloys, the base elements exhibit a wide mutual solubility, thus leading to form a solid solution with b.c.c. structure. However, it has been noticed that the hydrogenation performances of the resulting $\mathrm{Ti}_{\alpha} \mathrm{V}_{\beta} \mathrm{Cr}_{\gamma}$ alloys are influenced by different extrinsic factors, such as e.g. the method of synthesis and the thermal treatments [1-3]. However, it is worth mentioning that optimized compositions show a high hydrogen uptake with $\mathrm{H}_{\max }$ reaching up to $3.7 \mathrm{wt} . \%$. The reversible hydrogen storage capacity close to normal conditions was found to depend on the composition, i.e. the $(\mathrm{Ti}+\mathrm{V}) / \mathrm{Cr}$ ratio. Consequently, in the literature a large number of publications on many different $\mathrm{Ti}_{\alpha} \mathrm{V}_{\beta} \mathrm{Cr}_{\gamma}$ compositions can be found devoted to the analysis of hydrogen absorption/desorption characteristics. Furthermore it has been shown that the introduction of various additives, Hf-Ni, $\mathrm{Zr}-\mathrm{Ni}, \mathrm{LaNi}_{5}, \ldots$, leads to faster kinetics of the H-sorption processes. Undoubtedly, all these investigations make valuable steps towards a practical use of b.c.c. alloys and their derivatives as storage materials.

However, in order to propose a formula for the main b.c.c. alloy able to deliver challenging hydrogenation properties, it is necessary to well understand the impact of the metal composition on the
$\mathrm{H}$-sorption and related kinetic parameters. In a previous paper [4] we have reported on the impact of the relative content of $\mathrm{Ti}$ and $\mathrm{V}$ elements on the stability of $\mathrm{Ti}_{\alpha} \mathrm{V}_{\beta} \mathrm{Cr}_{\gamma}$ hydrides formed by solid-gas reaction. In parallel, when studying the hydrogen diffusion characteristics of Ti-V binary alloys [5], we showed that the process critically depends on the $\mathrm{Ti} / \mathrm{V}$ ratio. It was found that an increase of the concentration of elements forming hydrides ( $\mathrm{Ti}$ and $\mathrm{V})$ in $\mathrm{Ti}_{\alpha} \mathrm{V}_{\beta} \mathrm{Cr}_{\gamma}$ decreases the stability of the b.c.c. type hydrides by decreasing the desorption temperature $[4,6]$. This means that the chemical nature of $\mathrm{Ti}$ and $\mathrm{V}$ acts differently when forming multinary metal hydrides.

In order to better understand the reversibility of the sorption properties, we have investigated the effect of the vanadium content in $\left(\mathrm{TiCr}_{1.8}\right)_{100-x} \mathrm{~V}_{x}$ alloys for $x$ ranging from 0 to 100 . In most cases the hydrogen sorption characteristics of the alloys were studied by Pressure-Composition-Isotherms (PCI), implying a gas-solid reaction under hydrogen pressure, conducted at different temperature. Here, we used the electrolysis method, which has the advantage that the reaction to saturation occurs directly at room temperature. Moreover, the surface of the sample can be advantageously cleaned by an initial cathodic reaction. In addition, in this study we have not only investigated the effect of a progressive increase of the vanadium content in the $\left(\mathrm{TiCr}_{1.8}\right)_{100-x} \mathrm{~V}_{x}$ system, but also the parallel impact of 4 mol.\% of $\mathrm{Zr}_{7} \mathrm{Ni}_{10}$ as additive on the final stability and desorption kinetics of the $\mathrm{H}$-electro-charged materials. 


\section{Experimental}

At the first step, a large ingot of $\mathrm{C} 14$ Laves phase $\mathrm{TiCr}_{1.8}$ alloy was prepared from the elements (3N5 purity) using the HF melting technique in a watercooled crucible under argon atmosphere. In order to ensure homogeneity, the sample was re-melted three times. Then $\mathrm{Ti}_{\alpha} \mathrm{V}_{\beta} \mathrm{Cr}_{\gamma}$ alloys were synthesized via a comelting procedure of determined proportions of $\mathrm{TiCr}_{1.8}$ and $\mathrm{V}$ (4N purity). Ternary alloys $\left(\mathrm{TiCr}_{1.8}\right)_{100-x} \mathrm{~V}_{x}$, were prepared for $x=20,40,60$, and 80. Finally 4 mol. $\% \mathrm{Zr}_{7} \mathrm{Ni}_{10}$ was added via a third melting procedure, with the aim to dispose both of undoped ternary $\left(\mathrm{TiCr}_{1.8}\right)_{100-x} \mathrm{~V}_{x}$ alloys and $\mathrm{Zr}-\mathrm{Ni}$ doped composite samples.

Powders that had been mechanically crushed in a stainless steel mortar $(<200 \mu \mathrm{m})$ were hydrogenated in an autoclave under 20 bar $\mathrm{H}_{2}$ gas pressure $(5 \mathrm{~N}$ purity). The reaction was carried out at room temperature and finished in less than $3 \mathrm{~min}$ for most samples. Additional activation by cycling the temperature up to $200^{\circ} \mathrm{C}$ was needed for the samples having a high $\mathrm{V}$ content and no additive $(x=80,100)$. An estimate of the maximum hydrogen uptake was made by weighing the samples before and after hydrogenation. Bulk pieces cut from the ingots were hydrogen-charged by electrochemical reaction in an $1 \mathrm{M} \mathrm{KOH}$ solution, allowing the determination on the surface $\left(\sim 4 \mathrm{~mm}^{2}\right)$ of the hydrogen permeation rate and the hydrogen diffusion coefficient versus the vanadium content $x(\mathrm{~V})$. The $\mathrm{KOH}$ solution was prepared from high-purity reagent and de-ionized water. The temperature of the solution was maintained at $21^{\circ} \mathrm{C}$. Electrochemical measurements were carried out in a three-electrode electrochemical cell with the cathodic and anodic compartments separated by a porous glass diaphragm. The potentials were changed

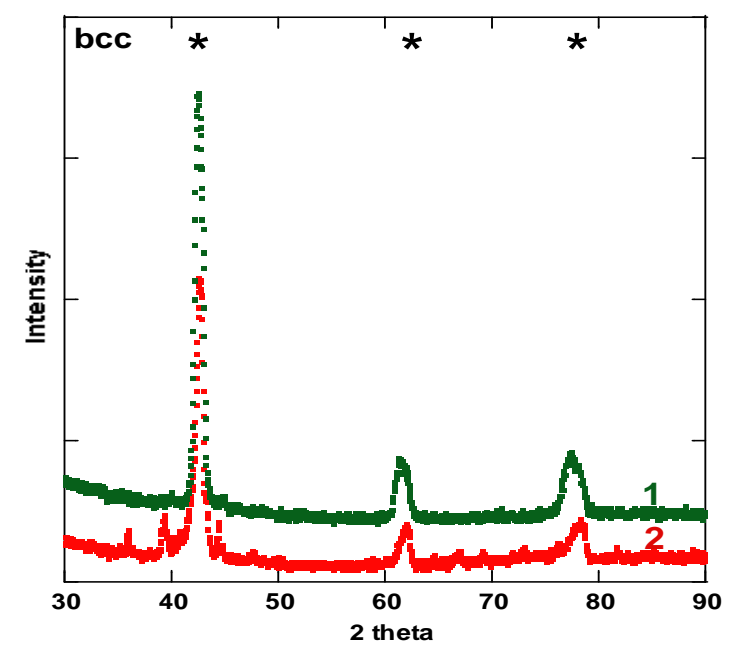

a from low to high cathodic polarizations. The electrochemical extraction method makes it possible to calculate the hydrogen reversible storage capacity $[7,8]$. The alloys were saturated with hydrogen by applying cathodic polarization to the working electrode $\left(i_{\mathrm{c}}=10-30 \mathrm{~mA} / \mathrm{cm}^{2}\right)$ for $15 \mathrm{~min}$ in an $1 \mathrm{~mol} / \mathrm{l}$ $\mathrm{KOH}$ solution, followed by electrochemical extraction of hydrogen from the saturated samples. The amount of extractible hydrogen was calculated according to $[7,8]$.

Structure and microstructure analyses were performed on all of the samples by using XRD $(\mathrm{Cu} \mathrm{K})$, SEM and EDX. DSC analysis was performed on the hydrogen gas charged samples to determine the kinetic of hydrogen desorption and the temperature of the phase transformation at the hydride decomposition. The microstructure and hydride characteristics of the $\mathrm{Ti}_{\alpha} \mathrm{V}_{\beta} \mathrm{Cr}_{\gamma}$-based alloys were compared with those obtained by alloying with the additive.

\section{Results}

\section{Structure}

XRD patterns were systematically recorded for powders of the different samples. All of the $\left(\mathrm{TiCr}_{1.8}\right)_{100-x} \mathrm{~V}_{x}$-based samples exhibited a pure b.c.c. structure, except the alloys with $x(\mathrm{~V})=20 \% \mathrm{~V}$, where a small amount of the C14-type $\mathrm{TiCr}_{2}$ phase was found (Fig. 1a), despite the fact that addition of $\mathrm{V}$ to $\mathrm{TiCr}_{1.8}$ should diminish the transformation temperature and inhibit the formation of Laves phases during the casting process. As already reported [1], the structural homogeneity of the $\mathrm{Ti}_{\alpha} \mathrm{V}_{\beta} \mathrm{Cr}_{\gamma}$ alloy can be influenced by the method of synthesis and thermal history. Because $\mathrm{Zr}_{7} \mathrm{Ni}_{10}$ was added to the $\mathrm{Ti}_{\alpha} \mathrm{V}_{\beta} \mathrm{Cr}_{\gamma}$

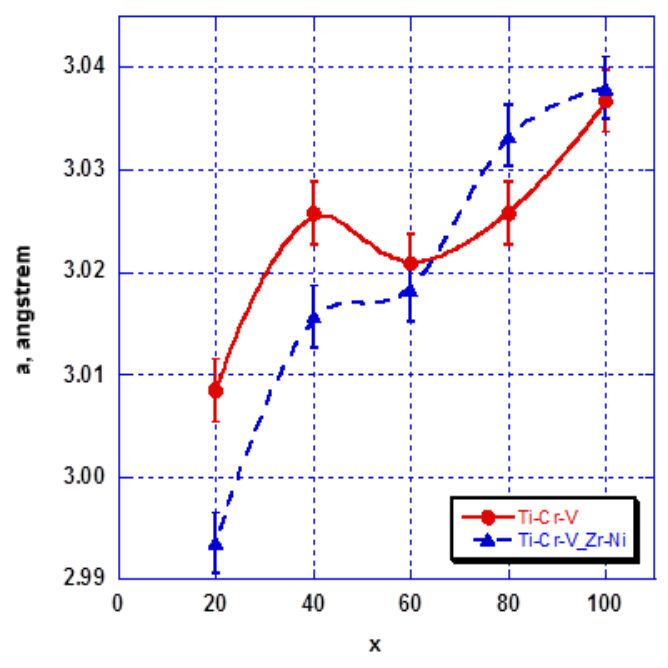

b

Fig. 1 XRD analysis. (a) Diffraction patterns: $1-\left(\mathrm{TiCr}_{1.8}\right)_{80} \mathrm{~V}_{20} ; 2-\left(\mathrm{TiCr}_{1.8}\right)_{80} \mathrm{~V}_{20}+\mathrm{Zr}_{7} \mathrm{Ni}_{10}$. The symbols (*) indicate lines corresponding to the b.c.c. phase, the other lines belong to the $\mathrm{C}$ 14-type $\mathrm{TiCr}_{2} \mathrm{phase}$ (b) Variation of the cell parameter for $\left(\mathrm{TiCr}_{1.8}\right)_{100-x} \mathrm{~V}_{x}$ and $\left(\mathrm{TiCr}_{1.8}\right)_{100-x} \mathrm{~V}_{x}+\mathrm{Zr}_{7} \mathrm{Ni}_{10}$. 
alloy via a third melting procedure, after the hightemperature additional treatment, the corresponding XRD patterns of the $\left(\mathrm{TiCr}_{1.8}\right)_{100-x} \mathrm{~V}_{x}+\mathrm{Zr}_{7} \mathrm{Ni}_{10}$ alloys showed completely homogenous b.c.c. phases, with the exception of the alloys with $x(\mathrm{~V})=20 \% \mathrm{~V}$. Apparently the added $\mathrm{Zr}_{7} \mathrm{Ni}_{10}$ phase stabilizes the Laves phase structure because the concentration of vanadium is close to the region on the phase diagrams where the $\mathrm{C} 14$ structure can be stabilized.

The unit cell parameter of the ternary alloys with and without $\mathrm{Zr}-\mathrm{Ni}$ additives increases with increasing $\mathrm{V}$ content, as shown in Fig. 1b, but the values always remain smaller than the cell parameter of pure vanadium. Moreover, for the composites $\left(\mathrm{TiCr}_{1.8}\right)_{100-x} \mathrm{~V}_{x}+4 \mathrm{~mol} . \% \mathrm{Zr}_{7} \mathrm{Ni}_{10}$, the b.c.c. lattice parameter $\left(a_{1}\right)$ appears systematically smaller than that measured for the ternary $\left(\mathrm{TiCr}_{1.8}\right)_{100-x} \mathrm{~V}_{x}$ alloys $\left(a_{2}\right)$, except close to the $x(\mathrm{~V})=80$ alloys.

We believe that the reduction of the b.c.c. cell parameter in $\left(\mathrm{TiCr}_{1.8}\right)_{100-x} \mathrm{~V}_{x}+4$ mol.\% $\mathrm{Zr}_{7} \mathrm{Ni}_{10}$, as compared with that of $\left(\mathrm{TiCr}_{1.8}\right)_{100-x} \mathrm{~V}_{x}$ for the same $x(\mathrm{~V})$, results from small but significant metal atom redistributions. We assume that a small amount of the alloyed nickel, as the smallest element, has been diluted in the ternary b.c.c. structure and, conversely, some amount of titanium, as the largest element of the b.c.c. phase, has been expulsed from the grains. Considering the mean increase of the cell parameter upon hydrogen uptake along the series, one may expect that upon increasing the $x(\mathrm{~V})$ concentration, the effective hydrogen content will decrease in the alloys. As a consequence, one would expect less and less effectiveness of the $\mathrm{Zr}_{7} \mathrm{Ni}_{10}$ additive versus $x(\mathrm{~V})$ on the microstructure and the related hydrogenation characteristics of the alloys $\left(\mathrm{TiCr}_{1.8}\right)_{100-x} \mathrm{~V}_{x}$.
In order to check this assumption, systematic SEM investigations were performed and in part already discussed in [9]. It can be underlined that for the ternary $\left(\mathrm{TiCr}_{1.8}\right)_{100-x} \mathrm{~V}_{x}$ alloys the SEM images appear homogeneous, but the distribution of elements exhibits peculiarities depending on the composition. For $\left(\mathrm{TiCr}_{1.8}\right)_{80} \mathrm{~V}_{20}$ the grain boundaries are clearly Ti-enriched as remains of the $\mathrm{TiCr}_{2}$-type phase shown by XRD. For all larger V contents, the alloys appear homogeneous. The b.c.c. phase was well crystallized during the progressive solidification process. On the contrary, The $\mathrm{Zr}_{7} \mathrm{Ni}_{10}$-doped alloys, for all formulas, besides the main $\mathrm{Ti}_{\alpha} \mathrm{V}_{\beta} \mathrm{Cr}_{\gamma}$ matrix the SEM images clearly show a secondary phase, which precipitates directly within and in between the main grains. The EDX profile analyses confirm that the precipitates are Ti-enriched. There, the Ti concentration, defined as the difference of concentration between the highest and lowest values both in the matrix and the intergranular phase, appears as large as 10 at.\%, as shown in Table 1. This gap represents a significant deviation of concentration within the b.c.c. phase, pointing out a major impact on the element distribution when $\mathrm{Zr}_{7} \mathrm{Ni}_{10}$ is alloyed. Quantitative SEM and EDX microanalyses reveal that, if the matrix contains a negligible concentration of $\mathrm{Zr}$, conversely at least $10 \%$ of the $\mathrm{Ni}$ of the boundary additive has migrated into the matrix grains.

Thus, the Ti-concentration increases dramatically at the boundary, with respect to the average concentration in the matrix (Fig. 2), while the concentrations of $\mathrm{Cr}$ and $\mathrm{V}$ seem almost unaffected by such a transfer. Moreover, it is worth noting that the width of the boundaries decreases nicely with increasing $x(\mathrm{~V})$, as shown in Figs. 2 a,b.
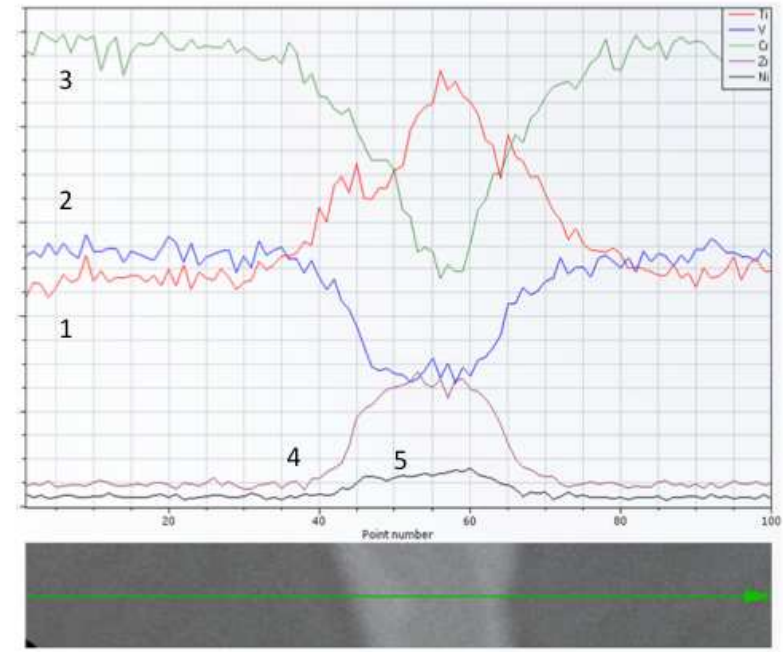

a
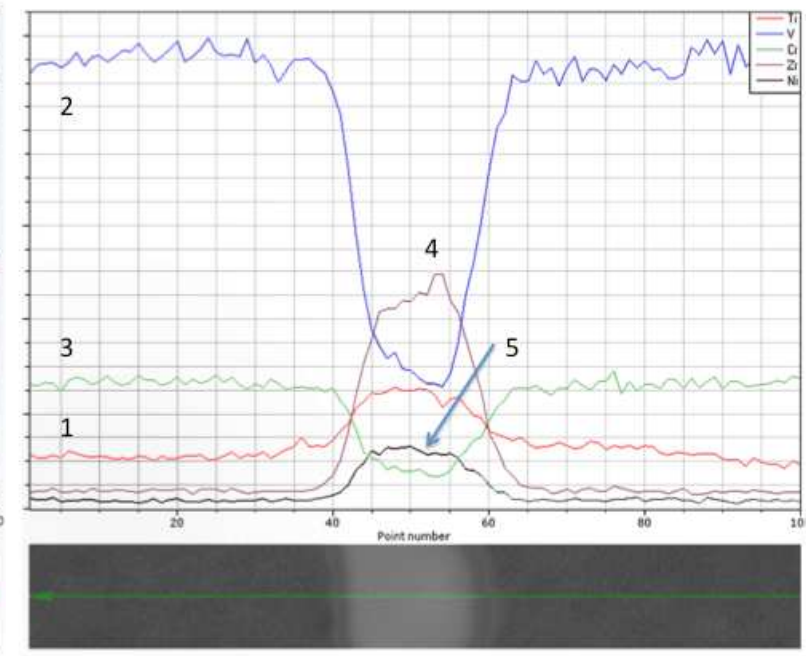

b

Fig. 2 Chemical analysis of (a) $\left(\mathrm{TiCr}_{1.8}\right)_{80} \mathrm{~V}_{20}+\mathrm{Zr}_{7} \mathrm{Ni}_{10}$ and (b) $\left(\mathrm{TiCr}_{1.8}\right)_{20} \mathrm{~V}_{80}+\mathrm{Zr}_{7} \mathrm{Ni}_{10}$ : $1-\mathrm{Ti}, 2-\mathrm{V}, 3-\mathrm{Cr}$, $4-\mathrm{Zr}, 5-\mathrm{Ni}$. Under the distribution of the elements the BSE-SEM images of the alloys are shown. 
N.E. Skryabina et al., Formation of microstructures in $\mathrm{Ti}-\mathrm{Cr}-\mathrm{V}$ alloys with high hydrogen sorption capacity

Table 1 Concentrations of $\mathrm{Ni}$ and $\mathrm{Ti}$ in the grains (matrix) and at the boundaries of the $\left(\mathrm{TiCr}_{1.8}\right)_{100-x} \mathrm{~V}_{x}+\mathrm{Zr}_{7} \mathrm{Ni}_{10}$ alloys.

\begin{tabular}{c|c|c|c|c}
\hline \multirow{2}{*}{$x$ at.\% V } & \multicolumn{2}{|c|}{ Grain, at.\% } & \multicolumn{2}{c}{ Grain boundaries, at.\% } \\
\cline { 2 - 4 } & $\mathrm{Ni}$ & $\mathrm{Ti}$ & $\mathrm{Ni}$ & $\mathrm{Ti}$ \\
\hline 20 & $3.81 \pm 0.61$ & $22.08 \pm 3.13$ & $10.63 \pm 0.25$ & $44.17 \pm 0.69$ \\
40 & $2.56 \pm 0.02$ & $17.28 \pm 0.03$ & $12.88 \pm 0.43$ & $39.37 \pm 2.10$ \\
60 & $2.03 \pm 0.09$ & $10.08 \pm 0.95$ & $14.69 \pm 0.09$ & $33.64 \pm 0.54$ \\
80 & $1.76 \pm 0.05$ & $6.05 \pm 0.04$ & $18.97 \pm 0.24$ & $31.84 \pm 0.53$ \\
\hline
\end{tabular}

\section{Electrochemical charging with hydrogen}

In general the hydrogen sorption characteristics of compounds are studied by PCI via a gas-solid reaction in hydrogen gas atmosphere versus pressure. Electrolytic hydrogen insertion is a method of great interest, since saturation occurs at room temperature and under normal pressure. One of the key parameters of the electrolytic process is the overvoltage $(\eta)$, which characterizes the level of energy for hydrogen electrochemical sorption, similar to the activation energy. The amount of hydrogen inserted into the metal depends in part on a mechanism called Hydrogen Evolution Reaction (HER), occurring on the surface of the material. In order to quantify the HER mechanism and then to compare the catalytic characteristics of the different alloys, cathodic polarization curves were recorded to determine the kinetic parameters as the Tafel coefficients $a_{\mathrm{k}}$ and $b_{\mathrm{k}}$. Accounting for the value of the Tafel slope versus $\eta$ and the weak dependence of the HER rate at constant $E$ (the potentials are expressed with respect to the standard hydrogen electrode) on the alkali concentration, one can expect that the hydrogen insertion into $\left(\mathrm{TiCr}_{1.8}\right)_{100-x} \mathrm{~V}_{x}$ proceeds according to a slow electrochemical desorption mechanism (Heyrovsky reaction):

$\mathrm{H}_{2} \mathrm{O}+e \rightarrow \mathrm{H}_{\mathrm{ads}}+\mathrm{OH}^{-}$(Volmer reaction)

$\mathrm{H}_{2} \mathrm{O}+\mathrm{H}_{\mathrm{ads}}+e \rightarrow \mathrm{H}_{2}+\mathrm{OH}^{-}$(Heyrovsky reaction) (2) The overvoltage of HER versus the $\mathrm{V}$ concentration in $\left(\mathrm{TiCr}_{1.8}\right)_{100-x} \mathrm{~V}_{x}$ with and without $\mathrm{Zr}_{7} \mathrm{Ni}_{10}$ additive, is shown in Fig. 3. A comparison of the two curves reveals that for the non-doped alloys $\left(\mathrm{TiCr}_{1.8}\right)_{100-x} \mathrm{~V}_{x}$, the overvoltage decreases progressively with increasing $x(\mathrm{~V})$, indicating that the reaction becomes easier. Addition of 4 mol. $\% \quad Z_{7} \mathrm{Ni}_{10}$ changes the values and the overall dependence of the overvoltage coefficient $(\eta)$ versus $x(\mathrm{~V})$ shows a non-monotonic variation. $30 \%$ reduction of the overvoltage was observed for the $x(\mathrm{~V})=20$ alloy doped with 4 mol.\% $\mathrm{Zr}_{7} \mathrm{Ni}_{10}$ with respect to the undoped alloy. For $x(\mathrm{~V})=40$ the reduction of the overvoltage diminishes to only $\sim 8 \%$, and for $x(\mathrm{~V})=60$ and 80 , the HER values remain similar.

For the electrochemical H-charging process, a low $\eta$ level and good hydrogen sorption properties are preferred. Krapivny [7] reports on the electrochemical extraction method and the results are shown in Fig. 4. For pure ternaries, good sorption properties were only found for $x(\mathrm{~V})=60$, but among the alloys doped with $\mathrm{Zr}_{7} \mathrm{Ni}_{10}$, much better properties were achieved for the materials with $x(\mathrm{~V})=20$ and 40 .

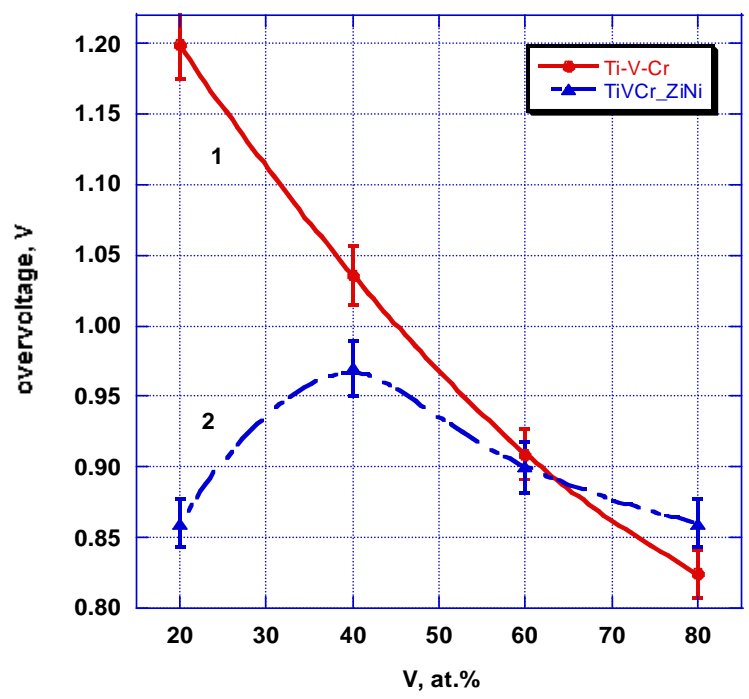

Fig. 3 HER overvoltage for $\left(\mathrm{TiCr}_{1.8}\right)_{100-x} \mathrm{~V}_{x}$ versus the $\mathrm{V}$ content: 1 - pure alloys, 2 - alloys with $\mathrm{Zr}_{7} \mathrm{Ni}_{10}$ additive.

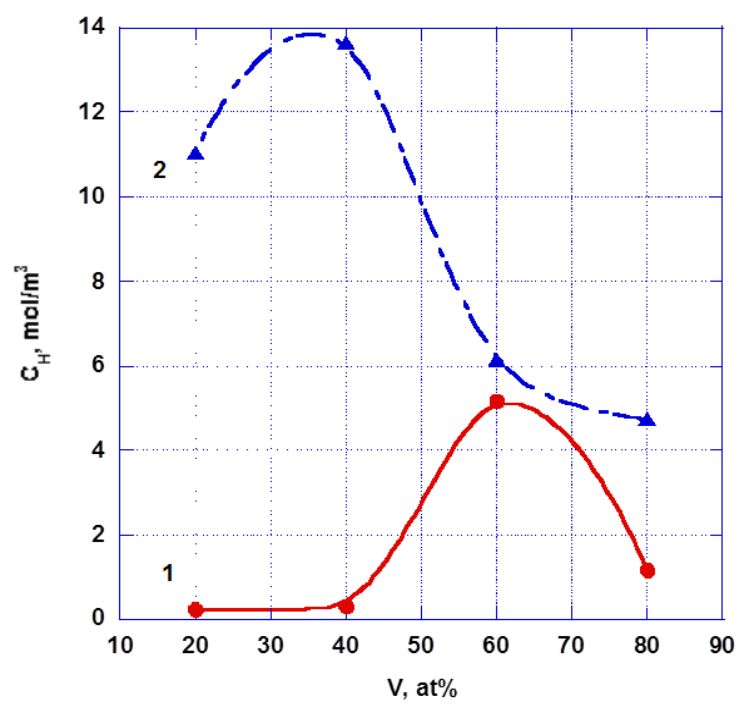

Fig. 4 Hydrogen uptake $\left(\mathrm{C}_{\mathrm{H}}\right)$ versus the $\mathrm{V}$ content for: $\left.1-\mathrm{TiCr}_{1.8}\right)_{100-x} \mathrm{~V}_{x}$, $2-\left(\mathrm{TiCr}_{1.8}\right)_{100-x} \mathrm{~V}_{x}+\mathrm{Zr}_{7} \mathrm{Ni}_{10}$. 
Fig. 5 presents the determination of the quantity of hydrogen adsorbed on the surface of the sample. Tentatively, the high values of hydrogen adsorbed by $\left(\mathrm{TiCr}_{1.8}\right)_{80} \mathrm{~V}_{20}+\mathrm{Zr}_{7} \mathrm{Ni}_{10}$, can be explained by the presence in the sample of the Laves phase. It should be emphasized that low values of hydrogen trapped on the surface suggest good sorption of hydrogen and its rapid diffusion deep into the material (as shown in Fig. 4 and Fig. 5). The difference between the kinetics of hydrogen permeation (diffusion) for the alloys with and without additives can be a direct consequence of the re-distribution of elements from and to the additive $\left(\mathrm{Zr}_{7} \mathrm{Ni}_{10}\right)$ in different parts of the alloy (Table 1).

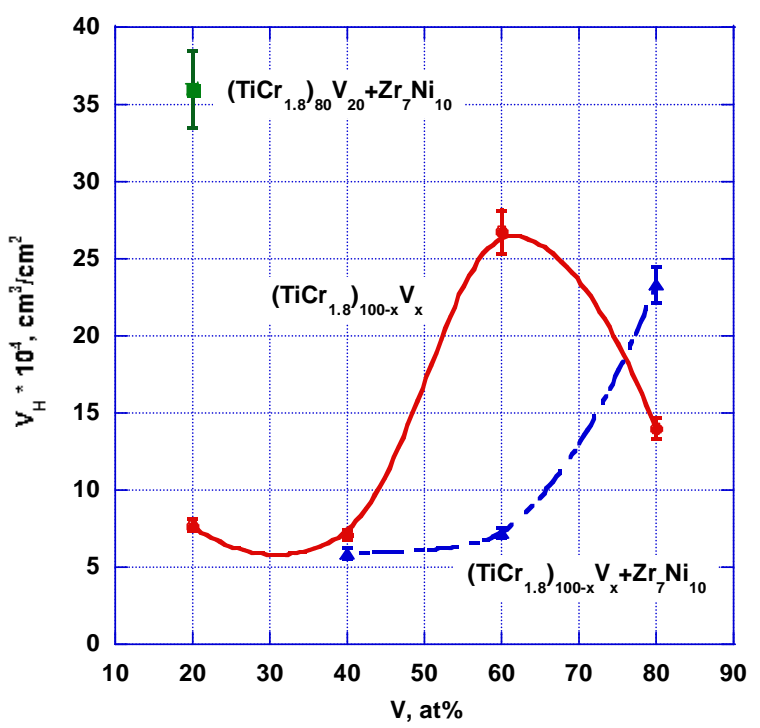

Fig. 5 Hydrogen adsorbed on a unit square of surface of the sample. The thickness of the hydrogen extraction layer is $1 \div 10 \mathrm{~nm}$.

\section{DSC analysis}

DSC curves were recorded in the temperature range 20 to $900^{\circ} \mathrm{C}$ for both of the hydrogenated series $\left(\mathrm{TiCr}_{1.8}\right)_{100-x} \mathrm{~V}_{x}$ and $\left(\mathrm{TiCr}_{1.8}\right)_{100-x} \mathrm{~V}_{x}+4$ mol.\% $\mathrm{Zr}_{7} \mathrm{Ni}_{10}$. It is worth recalling that DSC curves have already been recorded for many different hydrides of ternary Ti-V-Cr alloys, exhibiting different hydrogen uptakes. In general, two strong endothermic DSC peaks were found on the desorption curves, both varying in temperature and strength with the composition of the alloy $[5,10]$. The first endothermic peak at the lowest temperature, was assigned to a martensite-type transformation f.c.c.-b.c.c. of the hydride, and its intensity is directly related to the total amount of inserted hydrogen $[5,10,11]$. The second endothermic peak at the highest temperature was assigned to the decomposition of the b.c.c. hydride, and its characteristic temperature varies significantly with the $\mathrm{V}$ content $(x)$, as shown in Fig. 6 . The data show that for the pure ternary alloys, the b.c.c. stability of the hydride decreases with increasing $x(\mathrm{~V})$. Conversely, the $\mathrm{Zr}_{7} \mathrm{Ni}_{10}$ additive leads to an increase of the stability of the b.c.c. hydride with increasing $x(\mathrm{~V})$. It is worth underlining that for the $\left(\mathrm{TiCr}_{1.8}\right)_{100-x} \mathrm{~V}_{x}$ alloys with $x=20$ and 40 , the destabilization temperature of the b.c.c. hydrides is markedly lower than without additive.

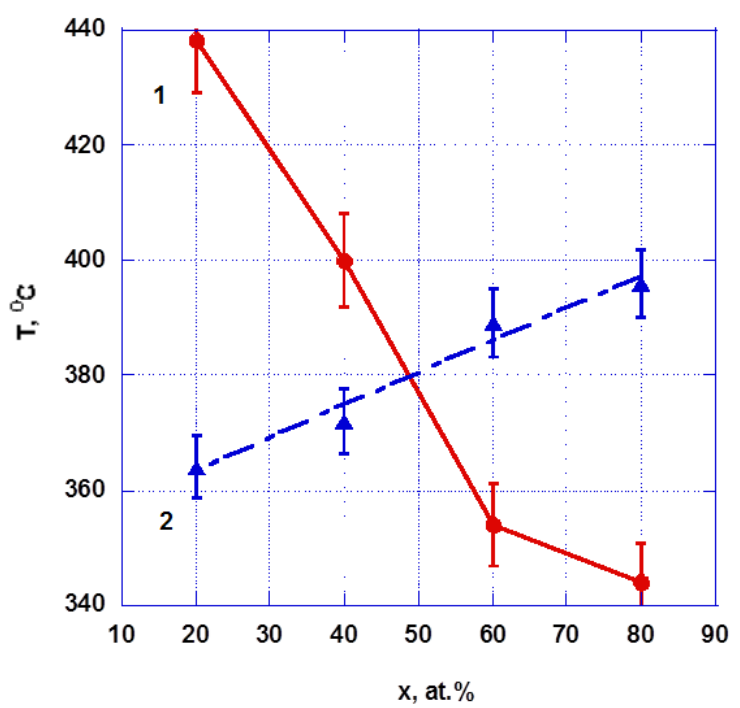

Fig. 6 DSC second dehydrogenation temperature peak of the hydrides of: $1-\left(\mathrm{TiCr}_{1.8}\right)_{100-x} \mathrm{~V}_{x}, 2-\left(\mathrm{TiCr}_{1.8}\right)_{100-x} \mathrm{~V}_{x}+\mathrm{Zr}_{7} \mathrm{Ni}_{10}$.

\section{Discussion}

In a previous paper [4] it was shown that when there are two components forming hydrides in the alloy ( $\mathrm{Ti}$ and $\mathrm{V}$ ), the stability of the hydride of the binary alloy markedly depends on the ratio $\mathrm{V} / \mathrm{Ti}$, in agreement with their respective binding energies. However, in the various $\mathrm{Ti}-\mathrm{V}$ hydrides hydrogen can be distributed with different bonding forces according to the local distribution of Ti and V. Clustering effects have been evidenced and the degree of metal ordering plays an important role in the $M-\mathrm{H}$, and consequently also in the $\mathrm{H}-\mathrm{H}$ interactions, enhancing by this the hydrogen dynamics. As a result, the increase of the vanadium concentration in the alloys facilitates the insertion of hydrogen and decreases the stability of the hydride in the ternary alloys.

The positive impact of additives such as $\mathrm{Zr}_{7} \mathrm{Ni}_{10}$ on hydrogen sorption and kinetic characteristics of ternary alloys was reported for the first time in [12]. It was suggested that the benefit of the additive should result from hydrogen permeation through a first oxide layer of the $\mathrm{C} 14$ Laves phase formed on the $\mathrm{TiCr}_{1.1} \mathrm{~V}_{0.9}+4 \mathrm{~mol} \% \mathrm{Zr}_{7} \mathrm{Ni}_{10}$ composite alloy [13]. The H-permeation allows forming cracks along the grain boundaries and exposes new surfaces to hydrogen, which can penetrate the b.c.c. grains. The additive $\mathrm{Zr}_{7} \mathrm{Ni}_{10}$ was considered as a catalyst related to the formation of the Laves phase, leading to a fast reaction with hydrogen and allowing easier 
pulverization of the samples than a bulk b.c.c. structure with high mechanical hardness. However, the presence of both a first layer of oxide and a second thin layer of $\mathrm{Zr}_{7} \mathrm{Ni}_{10}$ on the surface of the crystallites was not confirmed during the present studies. Besides, the initial $\mathrm{Zr}_{7} \mathrm{Ni}_{10}$ stoichiometry of the additive and consequently its crystal structure is not maintained during the co-melting operation [14].

Alternative situations must be considered, e.g. a Ti-rich layer formed around the grains. In [15] disproportionation of the $\mathrm{Zr}_{7} \mathrm{Ni}_{10}$ additive at the grain boundaries was mentioned, but no direct evidence was found to confirm that a high Ti-content layer could improve the overall hydrogenation kinetics. Besides, as reported in [16], a V-based b.c.c.-type hydrogen storage material including $\mathrm{Ti}, \mathrm{Cr}$ and $\mathrm{Ni}$ was found to exhibit interestingly high hydrogenation performances. A positive correlation between the $\mathrm{Ti}$ and $\mathrm{Ni}$ concentration in the matrix phase was proposed. The optimal $\mathrm{Ni}$ concentration is in the range $x(\mathrm{Ni})<y(\mathrm{Ti}) / 2$ and $<5.0$ at. $\% \mathrm{Ni}$. If the $\mathrm{Ni}$ concentration exceeds 5 at. $\%$, the hydrogen desorption capacity was shown to be low. The present results were analyzed accordingly, and the best ternary alloys should be formulated as $\left(\mathrm{TiCr}_{1.8}\right)_{100-x} \mathrm{~V}_{x}+4$ mol.\% $\mathrm{Zr}_{7} \mathrm{Ni}_{10}$ for $x(\mathrm{~V})=20$ to 40 .

\section{Conclusion}

In terms of microstructure and electro-hydrogenation properties, $\mathrm{Ti}_{\alpha} \mathrm{V}_{\beta} \mathrm{Cr}_{\gamma}$ alloys with b.c.c. structure, formulated as $\left(\mathrm{TiCr}_{1.8}\right)_{100-\mathrm{x}} \mathrm{V}_{\mathrm{x}}$, were compared with the same series of alloys with 4 mol.\% $\mathrm{Zr}_{7} \mathrm{Ni}_{10}$ additive. Due to the rather lower melting temperature of the $\mathrm{Zr}_{7} \mathrm{Ni}_{10}$ additive with respect to the ternaries, the final microstructure of $\left(\mathrm{TiCr}_{1.8}\right)_{100-x} \mathrm{~V}_{x}+4$ mol.\% $\mathrm{Zr}_{7} \mathrm{Ni}_{10}$ forms a $\mathrm{Ti}_{\alpha} \mathrm{V}_{\beta} \mathrm{Cr}_{\gamma}$ homogeneous b.c.c. matrix and the added elements form the basis of the grain boundaries. However, consistently with the XRD cell parameter analysis, SEM and EDX microanalysis revealed that a noticeable part of $\mathrm{Ti}$ migrates from the b.c.c. matrix towards the intergranular matter, forming a diffuse interface between the two zones; simultaneously a few at.\% of Ni migrate the opposite way.

For the pure and $\mathrm{Zr}_{7} \mathrm{Ni}_{10}$-doped ternaries, the reversible H-storage capacity was found to vary markedly with $x(\mathrm{~V})$, but in opposite ways when comparing the two series. The maximum reversible uptake capacities $C_{\mathrm{H}}$ were achieved with $\left(\mathrm{TiCr}_{1.8}\right)_{40} \mathrm{~V}_{60}$ and $\left(\mathrm{TiCr}_{1.8}\right)_{60} \mathrm{~V}_{40}+4 \mathrm{~mol} . \% \mathrm{Zr}_{7} \mathrm{Ni}_{10}$, respectively. For the $\left(\mathrm{TiCr}_{1.8}\right)_{100-x} \mathrm{~V}_{x}$ hydrides, the desorption temperature decreased markedly with $x(\mathrm{~V})$, conversely to what was observed for the series doped with 4 mol.\% $\mathrm{Zr}_{7} \mathrm{Ni}_{10}$. These results prove the strong impact of both the $\mathrm{V}$ concentration and the $\mathrm{Zr}-\mathrm{Ni}$ additive. There was no direct evidence indicating that the Ti-rich layer formed at the grain/boundary interface monitors the overall hydrogenation kinetics. The role of Ni should also be analyzed in more details, e.g. by studying $\mathrm{Ni}$-doped $\mathrm{Ti}_{\alpha} \mathrm{V}_{\beta} \mathrm{Cr}_{\gamma}$ alloys. To solve these questions, precise microanalyses must be performed before and after hydrogenation.

\section{Acknowledgement}

This work was supported by a RFBI grant, contract 14-08-96000_ural_a.

\section{References}

[1] H. Itoh, H. Arashima, K. Kubo, T. Kabutomori, J. Alloys Compd. 330-332 (2002) 287-291.

[2] T. Kabutomori, H. Takeda, Y. Wakisaka, K. Ohnishi, J. Alloys Compd. 231 (1995) 528-532.

[3] H. Arashima, F. Takahashi, T. Ebisawa, H. Itoh, T. Kabutomori, J. Alloys Compd. 356-357 (2003) 405-408.

[4] N.E. Skryabina, D. Fruchart, S. Miraglia, P. de Rango, M.G. Shelyapina, Solid State Phenom. 170 (2011) 302-306.

[5] N.E. Skryabina, D. Fruchart, M.G. Shelyapina, S. Dolukhanyan, A. Aleksanyan, J. Alloys Compd. 580 (2013) 94-97.

[6] E. Kurenkova, A. Vyvodtseva, M.G. Shelyapina, V.I. Chizhik, A.V. Ievlev, N.E. Skryabina, A.G. Aleksanyan, D. Fruchart, Solid State Phenom. 194 (2013) 254-257.

[7] N.G. Krapivny, Elektrokhimiya 17(5) (1981) 672-677.

[8] N.G. Krapivny, Elektrokhimiya 18(9) (1982) 1174-1178.

[9] N.E. Skryabina, D. Fruchart, N.A. Medvedeva, P. de Rango, A.A. Mironova, Solid State Phenom. 257 (2016) 165-172.

[10] S. Miraglia, D. Fruchart, N. Skryabina, M. Shelyapina, B. Ouladiaf, E.K. Hlil, P. de Rango, J. Charbonnier, J. Alloys Compd. 442 (2007) 49-54.

[11] E. Akiba, H. Enoki, Y. Nakamura, MRS Proc. 753 (2002), BB7.2 doi:10.1557/PROC-753BB7.2.

[12] J. Charbonnier, P. de Rango, D. Fruchart, S. Miraglia, S. Rivoirard, Patent CNRS WO2007096527, 2003.

[13] A. Martínez, D.S. dos Santos, Mater. Res. (Sao Carlos, Braz.) 15(5) (2012) 809-812.

[14] $5^{\text {th }}$ EC program - ENK-CT-2002-00600, Hydrogen Storage in Hydrides for Safe Energy Systems, HYSTORY project, Kiel Meeting, Nov. 2004, WP1 report.

[15] D. Planté, C. Raufast, S. Miraglia, D. Fruchart, P. de Rango, J. Alloys Compd. 580 (2013) 192-196.

[16] Y. Kamiya, K. Takahashi, M. Tsukahara, U.S. Patent 6,419,764 B1, 2002. 